WellBeing International

WBI Studies Repository

3-1998

\title{
Vocal Response to Pain in Piglets
}

\author{
Daniel M. Weary \\ Centre for Food and Animal Research \\ Leah A. Braithwaite \\ Centre for Food and Animal Research \\ David Fraser \\ Centre for Food and Animal Research
}

Follow this and additional works at: https://www.wellbeingintlstudiesrepository.org/farawel

Part of the Agribusiness Commons, Animal Studies Commons, and the Business Law, Public Responsibility, and Ethics Commons

\section{Recommended Citation}

Weary, D. M., Braithwaite, L. A., \& Fraser, D. (1998). Vocal response to pain in piglets. Applied Animal Behaviour Science, 56(2), 161-172.

This material is brought to you for free and open access by WellBeing International. It has been accepted for inclusion by an authorized administrator of the WBI Studies Repository. For more information, please contact wbisr-info@wellbeingintl.org.

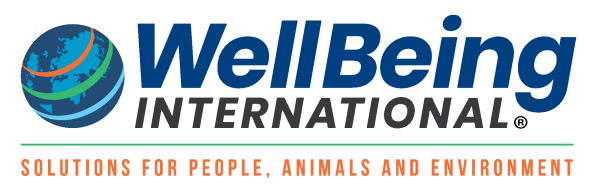




\title{
Vocal Response to Pain in Piglets
}

\author{
Daniel M. Weary, Leah A. Braithwaite, David Fraser
}

Centre for Food and Animal Research

\section{KEYWORDS}

pig welfare, pain, castration, vocalization

\begin{abstract}
Three experiments were performed attempting to establish the validity of vocal measures as an indicator of the immediate response to pain in domestic piglets. Vocalisations were measured while piglets were subjected to the routine farm practice of castration without anaesthetic, or restrained identically but not castrated (i.e., sham-castrated). In Experiment 1 we measured how calling changed during the different stages of the procedure, and in Experiments 2 and 3 we measured the effect of different restraint techniques. Piglets that were castrated produced significantly more high frequency calls $(>1000 \mathrm{~Hz}$ ) than sham castrates in all three experiments. In Experiment 1, we found the greatest differences between the castrated and sham piglets during the severing of the spermatic cords ( 1.0 high calls/s vs. 0.3 calls/s, $P<0.01$., and lesser differences when the scrotum was incised and the testicles extruded. In Experiments 2 and 3, castrates again produced high frequency calls at significantly faster rates than shams. The rate of low calls (frequency $<1000 \mathrm{~Hz}$ ), the mean frequency of the high calls, and mean call duration did not vary consistently between sham and castrated pigs. These results suggest that the increased rate of high calls is a reliable indicator of the pain due to castration. In Experiments 2 and 3, calling varied in response to how the piglets were restrained. However, there was no significant interaction between castration and restraint method for the rate of high calls, suggesting that the way in which the piglets were restrained did not affect the pain caused by castration.
\end{abstract}

\section{Introduction}

The vocalisations of animals can provide information about various aspects of their state. The begging calls of birds, for example, increase in rate after longer periods without food (e.g., Redondo and Castro, 1992). In a variety of species of birds and mammals, variation in the rate of calling seems to encode information about the caller's condition, including inadequate food intake or thermal environment (e.g., Evans, 1994; Weary and Fraser, 1995). In addition to this empirical evidence, there is a strong theoretical basis for predicting that, in many circumstances, vocal signals will provide parents with reliable information about the sorts of factors that can affect offspring survival (Godfray, 1995).

Thus the vocalisations of animals can provide listeners with information about the caller's functional state, but can these calls also provide information about a caller's affective state? In other words, can calling provide listeners with information about what an animal feels? This question is important, since the key issue for many in assessing animal welfare is how a procedure affects the subjective experiences of the animal (e.g., pain, suffering), not just the functioning of the body (Duncan, 1996; Fraser et al., 1997). The 
subjective experiences of animals cannot be observed directly (Kennedy, 1992), but it has been argued that at least certain subjective feelings, like an animal's sensation of pain, can be studied indirectly through features of the animal's behaviour, including vocalisations (e.g., Darwin, 1872; Dubner, 1994). Ultimately, the arguments for using indirect measures come from anatomical homology with humans and the presumption that higher vertebrates sharing similar sensory apparatus are likely to experience similar sensations and signal these sensations in similar ways (Stafleu et al., 1992).

Castration without anaesthetic is commonly performed on domestic piglets. The scrotum and testicles of pigs are well innervated (Ghoshal, 1975), and responses of piglets to castration can be mitigated by local anaesthetic (White et al., 1995). A number of studies have also pointed out differences in the behaviour of castrated and non-castrated pigs in the hours and days after the procedure. For example, Wemelsfelder and van Putten (1985) found that a number of behaviours (e.g., suckling, play, standing, time to lie down) were affected, and some behaviours emerged that seemed specific to the injury (e.g., sliding across floor on hind-quarters, flicking tail across scrotum). Based on this evidence, we postulated that castration without anaesthetic is painful to piglets, and thus proposed that castration provides a useful model system to validate behavioural indicators of this type of pain.

The aim of the experiments described here was to establish if vocal measures can serve as an immediate indicator of pain, using as our model the response of piglets to castration. The situations in which piglets vocalise are well known (e.g., Grauvogl, 1958), as are the effects of calls on listeners such as the sow (e.g., Weary et al., 1996). Establishing the differences in pain associated with different methods of castration is an important applied problem in its own right, providing an additional advantage to studying these calls. In an attempt to establish the generality of our results, we used different methods in each of three experiments, but in each case compared the vocal behaviour of animals castrated with those restrained similarly but not castrated. Using different methods of restraint also allowed us to address the specific applied question of whether calling, and thus the level of pain, varied in relation to how the procedure was performed.

\section{Animals, materials and methods}

\subsection{Apologia}

Experiments involving pain require some ethical justification. Every year, millions of piglets are castrated without anaesthetic as part of routine farm practices. The ultimate aim of this experimental work is to establish methods that will allow us to identify less painful ways of performing this and other procedures. In these experiments, no piglets were subjected to this procedure that would not have been castrated as part of routine farm and industry-wide procedures, and the piglets used were not bred for the purposes of this experiment, but rather for other work requiring standard castrated males. Piglets were also castrated according to standard farm procedure (as outlined below for Experiment 1) or with slight variations on this procedure (Experiments 2 and 3 ) thought to be less painful for the piglets.

\subsection{Housing and handling of animals}

All piglets were from our specific-pathogen-free Landrace $\times$ Yorkshire research herd and were tested at 8-12 days of age. Piglets were housed with sows kept in standard farrowing crates. Water was freely available from birth, and solid feed from 10 days after birth. Piglets were normally handled only once (on the day of birth) prior to castration. Subjects were always removed rapidly from their home pen and taken to the test room with a minimum of disturbance. Piglets were normally asleep before removal, and could be picked up gently without causing them to vocalise and without disturbing litter-mates or the sow. The same human handler restrained subjects throughout an experiment, although different restrainers were 
used in each of the three different experiments. Two different individuals castrated piglets, but preliminary analyses revealed no effect of the castrator on the piglets' vocal response.

\subsection{Experiment 1}

Piglets often call a great deal during restraint. The primary goal of all three experiments was to determine if castration does produce a vocal response clearly different from control animals restrained the same way. A secondary goal of Experiment 1 was to determine if the vocal response to castration varies between different components of the procedure. In this experiment, two piglets were tested from each of 13 litters. From each pair of litter-mates one was castrated and the other was restrained identically but not castrated ('sham castration').

From each litter, a pair of males was selected haphazardly and taken together to a test room visually and acoustically isolated from other animals. While one piglet was processed the other was kept in an enclosure in the same room. The order of the treatments (castration or sham castration) was random for the first litter, and alternated for subsequent litters. Castrations were separated into six stages during which the piglet's vocalisations were recorded: (1) One person (the 'restrainer') held the piglet in dorsal recumbency on a flat bench, holding front and rear legs securely in both hands, with the piglet's posterior facing a second person (the 'castrator') (3 s); (2) the castrator swabbed the area and scalpel with alcohol ( 5 s); (3) made a ventral-dorsal incision on the left side of the piglet's scrotum and extracted the testicle (4 s); (4) did the same to the piglet's right testicle $(5 \mathrm{~s})$; (5) severed the two spermatic cords with the scalpel (9 s); and (6) sprayed a topical disinfectant on the area of the incision (4 s).

The timing of the stages was the same for sham piglets, and the treatment of these piglets was also the same during stages 1, 2 and 6 . During sham stages 3 and 4, the dull side of the scalpel was drawn lightly across the scrotum in an identical fashion, and no incision was made. During stage 5 , sham piglets were held undisturbed. Slight variations in the timing of the stages did occur $( \pm 1.5 \mathrm{~s})$, so rates were calculated using durations of the stages as measured from video recordings.

\subsection{Experiments 2 and 3}

In establishing the validity of vocal measures as indicators of pain due to castration, we felt it was important to replicate Experiment 1 using alternative but comparable procedures. One common source of variation in castration techniques is the way that piglets are restrained. Thus in Experiments 2 and 3 we compared the piglet's response to castration when restrained using the method favoured at our own research barn (held on a bench as described above), with two alternative techniques that some producers argue make castration less painful for the piglet: suspended by the rear legs (Experiment 2) and held in a v-trough (Experiment 3).

In Experiment 2, four piglets were tested from each of 10 litters. Within each litter, piglets were haphazardly selected from the available males, and randomly assigned to the four cells of a $2 \times 2$ factorial design. Piglets were brought individually to a visually and acoustically isolated test room, where they were either castrated or sham-castrated while restrained in one of two different ways. Two piglets from each litter were held in dorsal recumbency on a flat bench as in Experiment 1, and were either castrated or sham-castrated. The two other piglets from each litter were suspended by the rear legs with the dorsal surface facing the restrainer and ventral surface facing the castrator, and again either castrated or shamcastrated. As in Experiment 1, recording began when the subject was first restrained and ended after the topical disinfectant was applied. This period was standardised to exactly $90 \mathrm{~s}$. A longer period was allowed than in Experiment 1 to ensure that all piglets could easily be processed within the period, and because in this experiment the scrotum was cleaned with soap and a gauze pad before being rinsed with 
alcohol. All other stages were as described for Experiment 1, but the timing of the individual stages was not standardised and calls were not analysed by stage.

In Experiment 3, four piglets were tested from each of nine litters in a $2 \times 2$ factorial design. We used the procedures of Experiment 2 with the following exceptions. Two piglets from each litter were held in dorsal recumbency on a flat bench, and were either castrated or sham-castrated. The other two were also held in dorsal recumbency but in a v-trough. The trough consisted of two pieces of plywood $(0.3 \times 0.9 \mathrm{~m}$. joined along the long edge at a $90^{\circ}$ angle, with the interior of the trough facing upward and padded with terry-cloth towelling. The piglet was held so that its posterior extended slightly beyond the end of the trough making the scrotum easily accessible to the castrator. In this experiment, subjects were allowed 30 $s$ to settle before recording began. The subjects' calls were recorded from the beginning of the cleaning of the scrotal area (i.e., stage 2 in Experiment 1) to the time the disinfectant was applied, a period standardised to $45 \mathrm{~s}$. A shorter period was chosen because Stage 1 recordings were not included in this experiment, and because we found that piglets could be processed within a shorter time than the $90 \mathrm{~s}$ allowed in Experiment 2.

\subsection{Analyses}

In all experiments, calls were recorded on a Sony TCD-D3 DAT recorder connected to a Beyer Dynamic MCE86 N(C) microphone $40 \mathrm{~cm}$ from the subject's mouth. Taped sequences were digitised (16-bit, 20 $\mathrm{kHz}$ sampling rate) using Signal software (Engineering Design, 1991). The time waveform of each sequence was subjected to a smoothing routine (three times at $20 \mathrm{~ms}$ and then three more times at 50 $\mathrm{ms}$ ) to reduce the effect of very short energy peaks and troughs. Individual vocalisations were identified automatically by the program as separate from background noise when the energy rose to at least four times that of the background level for more than $50 \mathrm{~ms}$. The time waveform of each vocalisation was then used to calculate call duration (ms). As a measure of call frequency $(\mathrm{Hz})$ we used the frequency in the call that was highest in amplitude. This frequency was identified automatically from the power spectrum using the ME/F command in Signal. All measures were calculated by Signal, and thus were not subject to observer bias.

As described in Section 3, the distribution of the call frequency was bi-modal, so calls could be classified as either high ( $\geq 1000 \mathrm{~Hz}$. or low frequency ( $<1000 \mathrm{~Hz}$ ). For each pig we calculated the rate of high and low calls, the mean duration of all the calls, and the mean frequency of the high calls. The mean frequency of the low calls was analysed separately in a preliminary analysis, but was not found to vary significantly with any of the treatments.

Dependent variables (after square-root transformation) were analysed statistically using the GLM procedure in SAS (release 6.08). For all three experiments, the model included the litter mean (with either 12, 9 or $8 \mathrm{df}$ ), the effect of castration (1 df), and an effect of order (1 df). In Experiments 2 and 3 the model also included the effect of restraint method (1 df), and the 2- and 3-way interaction terms (i.e., castration $\times$ order, castration $\times$ restraint method, order $\times$ restraint method, and castration $\times$ order $\times$ restraint method. (4 df). Measures of the mean call frequency and mean call duration could not be calculated for three subjects that did not call in Experiment 3. For call rates, however, each subject (even those that did not call) contributed one observation.

Least-square means and standard errors are quoted throughout. To present values in the original scale, means of the square-root values were back-transformed. Back-transformation causes standard errors to be non-symmetrical, so for any given comparison, a negative standard error is quoted for the higher of the two means and a positive standard error is quoted for the lower mean. 
Fig. 1. Spectrogram of four calls produced by a 10-day-old piglet during and just after the severing of the spermatic cord. Calls 1, 2 and 4 were classified as high calls, and call 3 was classified as a low call.

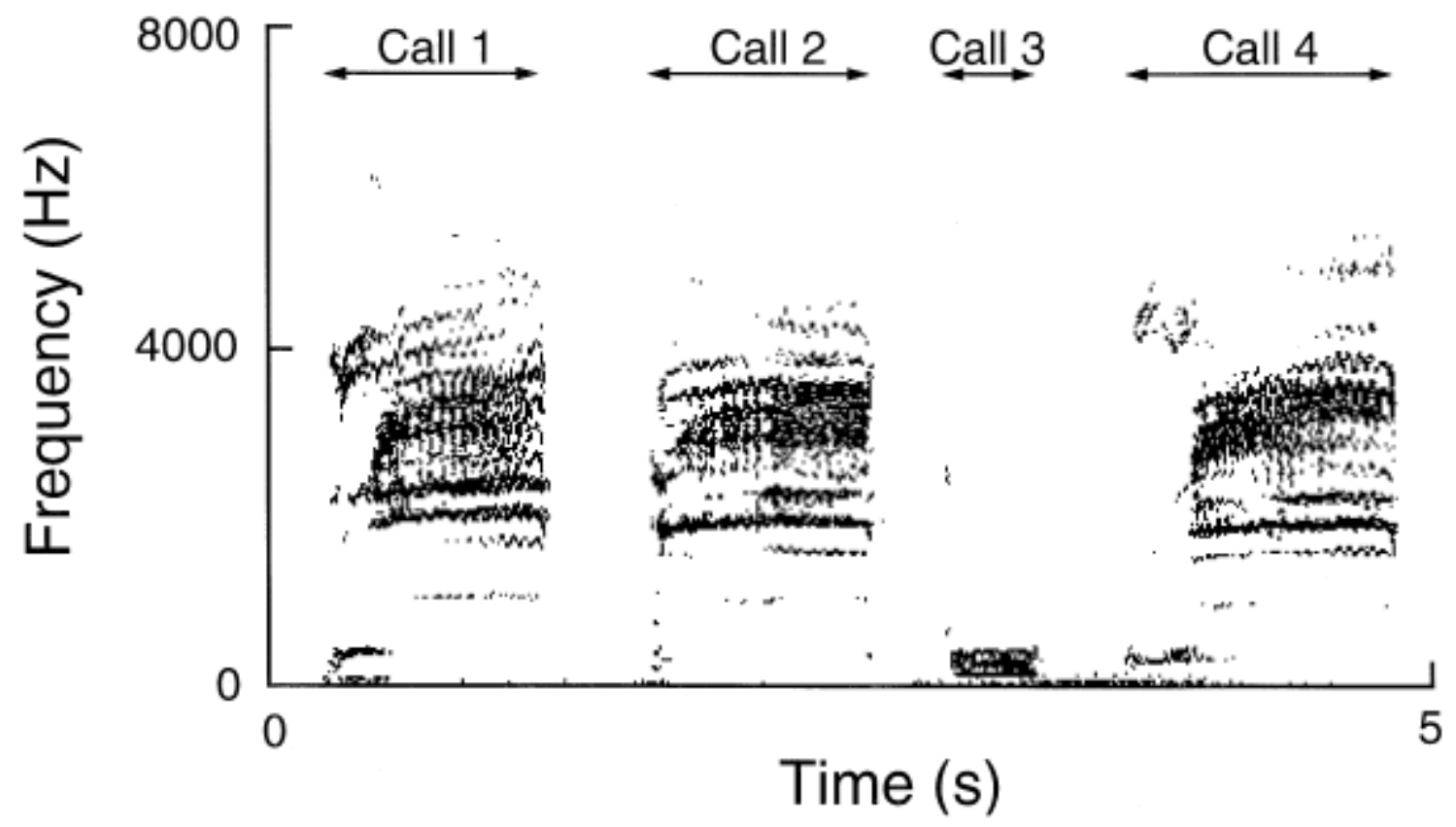

Fig. 2. The number of calls in 100-Hz intervals from 0 to $8000 \mathrm{~Hz}$ for the 2955 calls measured in this study. The distribution shows two distinct peaks: one between 100-600 Hz and the second between $3000-4000 \mathrm{~Hz}$, divided by a trough at approximately $1000 \mathrm{~Hz}$.

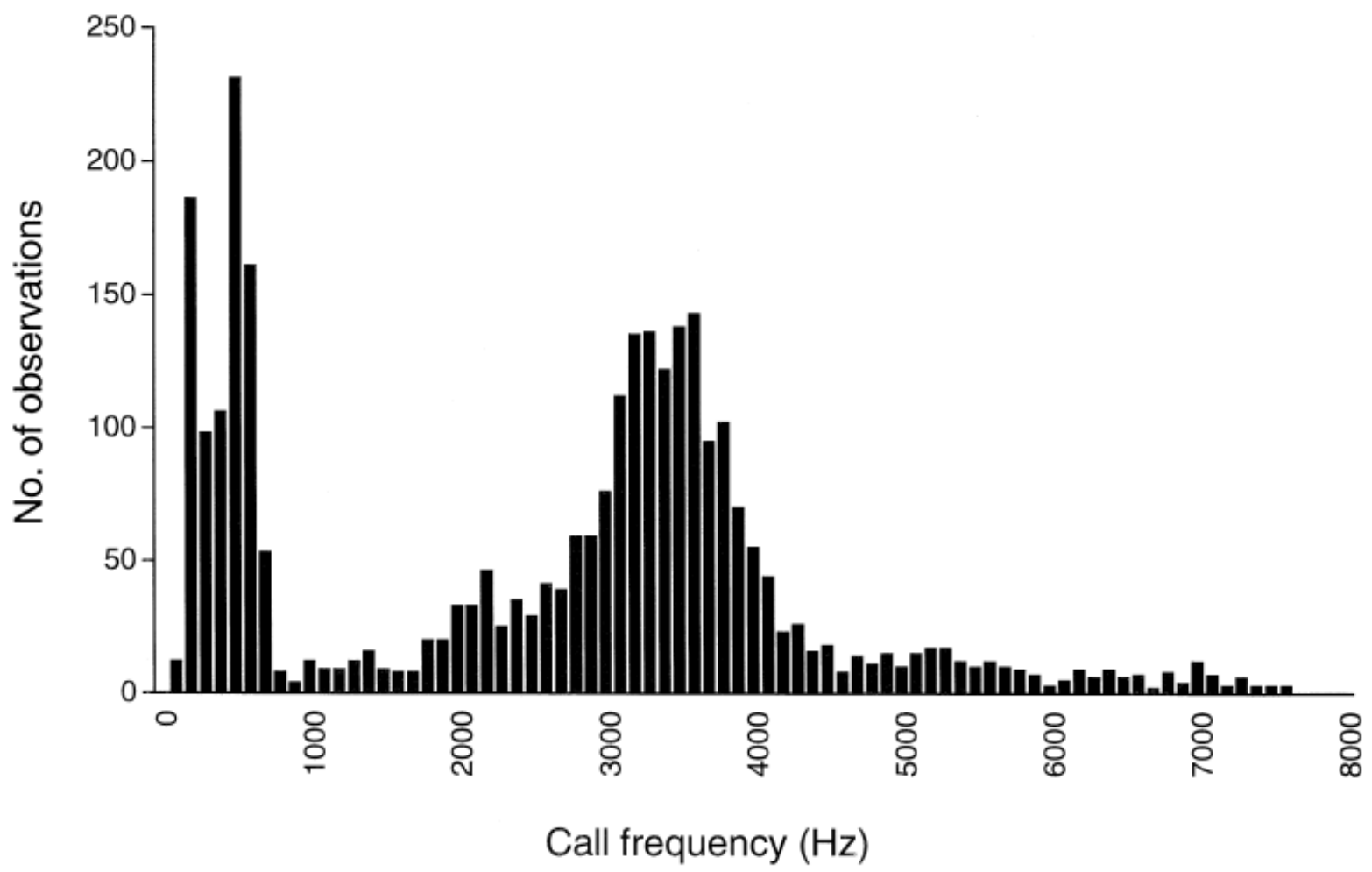




\section{Results}

A representative sequence of calls produced by a piglet during castration is illustrated in Fig. 1. Vocalisations produced by pigs in all three experiments were highly variable, both during a procedure on a given animal, and between animals. Frequencies of individual calls were distributed bi-modally, with the trough occurring at approximately $1000 \mathrm{~Hz}$ (Fig. 2). This bi-modality provided a basis for dividing calls into two classes: 'high calls' of greater than $1000 \mathrm{~Hz}$, and 'low calls' of less than $1000 \mathrm{~Hz}$.

Table 1. The vocal response of piglets in Experiment 1, during each of the six stages

\begin{tabular}{|c|c|c|c|c|}
\hline \multirow[t]{2}{*}{ Stage and treatment } & \multicolumn{2}{|l|}{ Rate (calls/s) } & \multirow[t]{2}{*}{ Duration (ms) } & \multirow[t]{2}{*}{ Frequency of high calls (Hz) } \\
\hline & High calls & Low calls & & \\
\hline \multicolumn{5}{|l|}{ Stage 1-restraint } \\
\hline Castrated & $0.57+0.24$ & $0.10-0.05$ & $304+46$ & $3559+351$ \\
\hline Sham & $0.69-0.22$ & $0.03+0.04$ & $336-49$ & $3750-320$ \\
\hline \multicolumn{5}{|l|}{ Stage 2-cleaning } \\
\hline Castrated & $0.81-0.20$ & $0.05+0.1$ & $449-94$ & $3989-212$ \\
\hline Sham & $0.52+0.18$ & $0.08-0.02$ & $352+107$ & $3820+284$ \\
\hline \multicolumn{5}{|c|}{ Stage 3-incision and extraction left } \\
\hline Castrated & $0.64-0.21$ & $0.01+0.03$ & $577-51$ & $3657+261$ \\
\hline Sham & $0.37+0.20$ & $0.07-0.05$ & $532+49$ & $4022-317$ \\
\hline \multicolumn{5}{|c|}{ Stage 4-incision and extraction right } \\
\hline Castrated & $0.76-0.15$ & $0.01-0.01$ & $660-71$ & $3657+261$ \\
\hline Sham & $0.28+0.09^{*}$ & $0.01+0.01$ & $613+108$ & $3672-368$ \\
\hline \multicolumn{5}{|l|}{ Stage 5-cutting cords } \\
\hline Castrated & $0.98-0.19$ & $0.02+0.02$ & $587-71$ & $3565+201$ \\
\hline Sham & $0.31+0.11^{\star *}$ & $0.05-0.02$ & $379+86$ & $4485-336$ \\
\hline \multicolumn{5}{|l|}{ Stage 6-disinfectant } \\
\hline Castrated & $0.12-0.06$ & $0.09-0.04$ & $428+81$ & $3272+465$ \\
\hline Sham & $0.04+0.03$ & $0.04+0.04$ & $439-109$ & $4560-853$ \\
\hline
\end{tabular}

Least-square means ( + or - s.e.). are shown by castration treatment for the four different response measures:

high calls (i.e., those $>1000 \mathrm{~Hz}$ ), low calls $(<1000 \mathrm{~Hz}$ ), call duration, and mean frequency of the loudest band of the high calls.

Significant effect of castration is designated by * $(P-0.05)$ or ${ }^{\star \star}(P<0.01)$.

\subsection{Experiment 1}

Both castrated and sham-castrated piglets called a great deal during the initial stages of restraint (Table 1 ). The rate of high calls declined steadily over the course of the procedure for sham piglets, but castrated piglets continued to produce these calls at a fast rate during the first 5 of the 6 stages.

Because the difference between the castrated and sham piglets varied with the stage of the castration, we compared the calls from the two treatment groups separately for each stage. Castrated piglets produced high calls at a significantly faster rate than sham piglets during the fourth stage (second incision and extrusion) and fifth stage (severing the spermatic cord) of the procedure. The difference between 
castrated and sham-castrated piglets was not significant during the other stages or for the other response measures.

In this experiment, the two piglets used from each litter were removed from the pen and brought to the test room together. Thus the second piglet waited in the test room while the first was processed, and was therefore, exposed to any calls the first piglet produced. Calling was affected by the order in which the two subjects were tested: the second piglet tested produced high calls at a faster rate than the first piglet during the second stage $(1.18-0.24$ vs. $0.28+0.14$ high calls/s; $P<0.01)$, third stage $(1.01-0.32$ vs. $0.16+0.14$ high calls/s; $P<0.02$., and fourth stage $(0.68-0.14 \mathrm{vs}$. $0.33+0.10$ high calls/s; $P=0.07)$ of the procedure. Differences were not significant during other stages or for other call measures.

The fact that piglets called more when tested second may have obscured our within-litter comparison of castrated vs. sham-castrated piglets. We therefore performed an among-litter test of the castration treatment examining only the data from the first piglet tested in each litter. Like the within-litter test, this comparison also showed that the castrated piglets produced high calls at a significantly faster rate than sham piglets during stage $4(0.65-0.21$ vs. $0.11+0.12$ high calls/s; $P<0.05)$ and stage $5(1.08-0.15$ vs. $0.18+0.20$ high calls $/ \mathrm{s} ; P<0.01)$. This comparison also revealed that castrated piglets produced calls with a longer mean duration $(753-218$ vs. $230+89 \mathrm{~ms} ; P=0.05)$ than sham piglets during the third stage. Differences at other stages and for other response measures were not significant.

Table 2. The vocal response of piglets in Experiments 2 and 3

\begin{tabular}{|c|c|c|c|c|}
\hline \multirow[t]{2}{*}{ Experiment and treatment } & \multicolumn{2}{|c|}{ Rate (calls/s) } & \multirow[t]{2}{*}{ Duration (ms) } & \multirow[t]{2}{*}{ Frequency of high calls (Hz) } \\
\hline & High calls & Low calls & & \\
\hline Experiment 2 & $C * *$ & $\mathrm{H} * *$ & & \\
\hline \multicolumn{5}{|l|}{ Castrated } \\
\hline Bench & $0.62-0.13$ & $0.15-0.03$ & $423-50$ & $3284-115$ \\
\hline Suspended & $0.40+0.10$ & $0.07+0.03$ & $414+52$ & $3045+149$ \\
\hline \multicolumn{5}{|l|}{ Sham } \\
\hline Bench & $0.29-0.08$ & $0.12-0.03$ & $359-46$ & $3146-162$ \\
\hline Suspended & $0.14+0.06$ & $0.04+0.02$ & $335+47$ & $3033+132$ \\
\hline Experiment 3 & $C * *$ & $H^{* *}$ & & \\
\hline \multicolumn{5}{|l|}{ Castrated } \\
\hline Bench & $0.20-0.05$ & $0.07+0.02$ & $324+46$ & $3412+143$ \\
\hline V-trough & $0.18+0.05$ & $0.12-0.03$ & $332-44$ & $3786-149$ \\
\hline \multicolumn{5}{|l|}{ Sham } \\
\hline Bench & $0.07-0.03$ & $0.03+0.02$ & $400-61$ & $3595-185$ \\
\hline V-trough & $0.09+0.03$ & $0.13-0.03$ & $262+41$ & $3349+169$ \\
\hline
\end{tabular}

Least-square means ( + or -1 s.e.) are shown for the four different response measures and for each of the four cells (i.e., castration and restraint treatments each with two levels) from these experiments. No interaction terms were significant.

Significant castration effects are designated by $C *(P<0.05$. or $C * *(P<0.01)$; handling effects are designated by $\mathrm{H}^{*}(P<0.05)$ or $\mathrm{H}^{* *}(P<0.01)$.

\subsection{Experiment 2}

In Experiment 2, castrated piglets again produced significantly more high calls than sham piglets (Table 2). Piglets suspended by their rear legs tended to produce fewer high calls than those restrained on the bench $(P<0.1)$, but there was no interaction between the effects of castration and restraint method. 
Castrated piglets also tended to produce more low calls than sham piglets, and piglets held on the bench produced significantly more of these calls than did those suspended by their rear legs (Table 2 ).

\subsection{Experiment 3}

Again, castrated piglets produced significantly more high calls than the shams (Table 2), but there was no effect of restraint method (held on the bench or in the v-trough) and no interaction. For low calls, there was no significant difference between sham and castrated piglets, but piglets restrained in the v-trough produced significantly more low calls than those restrained on the bench. There was no significant interaction between restraint method and castration, and differences were not significant for the other response measures.

\section{Discussion}

The rate of high calling was the one vocal measure that was consistently greater for castrated than for sham piglets. If we accept the postulate that castration caused pain and the sham procedure did not, then these results suggest that an increased rate of high calls is a reliable indicator of pain. For this reason, we base our conclusions about pain on this measure.

Results from another recent study support the conclusion that differences in vocal measures can relate to the pain experienced by piglets during castration. White et al. (1995) castrated piglets with or without a local anaesthetic (lidocaine hydrochloride injected subcutaneously into the scrotum over each testicle, 3 min before castration), and found that the anaesthetic reduced the frequency of calls produced during castration.

Vocal responses are listed in several guidelines as indicators of pain in laboratory animals (Lineberry, 1981; Morton and Griffiths, 1985), and some studies have attempted to use vocalisations in response to pain in other animals. For example, Mellor (1991) noted whether calling occurred during castration of lambs, kids and calves, as did Lay et al. (1992a,b) during branding of calves and cattle. Noonan et al. (1994) measured call rates of pigs during teeth clipping, tail docking and ear notching, and Noonan et al. (1996) measured call rates of different breeds of dogs during tail docking. Some of the best developed work on vocal measures of pain has been that on evaluating procedures performed on human infants (e.g., Craig, 1994). For example, a number of studies have shown that certain cry features increase in response to circumcision without anaesthetic (Porter et al., 1986, 1988) and minor procedures such as heel-lancing and injections (Grunau et al., 1990; Craig et al., 1993).

It should be noted that different vocal measures have been used in different studies. Some studies have simply noted the occurrence of vocalisations (e.g., Mellor, 1991; Lay et al., 1992a, while other have measured total call rates and rates of different types of calls (e.g., Noonan et al., 1994, 1996). Work on the cries of human infants has focused on measures such as the latency to cry, duration of cries, and aspects of the fundamental frequency such as the maximum value in any one cry and extent of variation (e.g., Grunau et al., 1990). Clearly, not all measures will be useful in each species, and the choice of variable may affect the conclusions of the study.

In previous work on piglet castrations, researchers have measured the frequency in the call that is highest in amplitude (Wemelsfelder and van Putten, 1985; White et al., 1995). In the current study, we also measured this frequency but found two classes of calls as shown in Fig. 2. The rate of high frequency calls increased significantly in response to castration, but we did not find consistently significant differences in terms of our other measures (rate of low frequency calls, average frequency of high or low calls, and the call duration). In other work (unpublished data), we have measured a large number of call 
characteristics including aspects of the fundamental frequency and variation in the frequency over time, but again did not find consistently significant differences in response to castration.

\subsection{Applied issues}

One advantage of doing experiments on piglet castration, is that our results can also begin to address certain animal welfare concerns. Specifically these experiments allowed us to determine if the stage of the procedure (Experiment 1) or handling method (Experiments 2 and 3) affected the immediate pain due to castration.

In Experiment 1, the difference in the rate of high calls between castrated and sham piglets was much greater during the later stages of the procedure. It is impossible to avoid confounding time with the different steps in castration, but the results suggest that the later stages of castration, especially the severing of the spermatic cords, may be the most painful. This result is of some practical concern as producers sever the spermatic cord in many different ways: some simply tear the cord by pulling, others crush it between the thumb and forefinger, and still others use a scalpel either to sever the cord (as we did in these experiments) or to create a jagged cut by scraping the cord so as to minimise bleeding. Certain of these options might be more painful than others, and vocal measures might allow us to identify the least painful options.

In Experiment 1, piglets produced more high calls if they were the second processed from each litter, and thus had heard the calls of their brothers as they were castrated or sham-castrated. Although a controlled experimental test of this 'pre-exposure' effect is required, this finding suggests that hearing calls may distress other piglets. Sows will respond to these calls by standing, approaching the caller, and vocalising themselves (unpublished data). These results tend to support the recommendation (Connor, 1993) that castration be performed in a location acoustically isolated from other animals.

The effects of restraint method were investigated in Experiments 2 and 3. In neither experiment was there a significant interaction between the castration and handling method for the rate of high calls, indicating that the method of handling did not affect the pain due to castration. In fact, there was no significant interaction for any of the response measures. In Experiment 2, piglets suspended by their rear legs produced low calls at a significantly slower rate than those piglets restrained on the bench. In Experiment 3 , piglets restrained on the bench produced low calls at a significantly lower rate than those restrained in the trough. These differences in the rate of low calls may reflect other differences in the state of the animals, or even the ease vocalizing from that position, but should not be taken as evidence that the method of restraint influences pain.

\section{Acknowledgements}

We are grateful to Mike Appleby, Barry Milligan, Ed Pajor and Allison Taylor for their comments on previous drafts of this manuscript, and to the staff of our research barn for their help and cooperation in performing these experiments.

\section{References}

Connor, M.L., 1993. Recommended Code of Practice for Care and Handling of Pigs. Agriculture Canada, Ottawa.

Craig, K.D., 1994. Emotional aspects of pain. In: Wall, P.D., Melzack, R., (Eds.), Textbook of Pain, 3rd edn. Churchill Livingstone, Edinburgh, pp. 261-274. 
Craig, K.D., Whitfield, M.F., Grunau, R.V.E., Linton, J., Hadjistavropoulos, H.D., 1993. Pain in the preterm neonate: behavioural and physiological indices. Pain 52, 287-299.

Darwin, C., 1872. The Expression of the Emotions in Man and Animals. John Murray, London.

Dubner, R., Methods of assessing pain in animals. In: Wall, P.D., Melzack, R. (Eds.), Textbook of Pain, 3rd edn. Churchill Livingstone, Edinburgh, (1994), pp. 293-302.

Duncan, I.J.H., 1996. Animal welfare defined in terms of feelings. Acta Agric. Scand. Sect. A., Anim. Sci. 27, 29-35, Suppl.

Engineering Design, 1991. Signal: User's Manual, Engineering Design. Belmont, MA.

Evans, R.M., 1994. Cold-induced calling and shivering in young American white pelicans: honest signalling of offspring need for warmth in a functionally integrated thermoregulatory system. Behaviour 129, 13-34.

Fraser, D., Weary, D.M., Pajor, E.A., Milligan, B.N., 1997. A scientific conception of animal welfare that reflects ethical concerns. Anim. Welfare 6, 187-205.

Ghohal, N.G., 1975. Abdominal, pelvic and caudal autonomic innervation. In: Getty, R. (Ed.), The Anatomy of the Domestic Animals, Vol. 2. Saunders, Philadelphia, pp. 1403-1408.

Godfray, H.C.J., 1995. Signaling of need between parents and young: parent-offspring conflict and sibling rivalry. Am. Nat. 146, 1-24.

Grauvogl, A., 1958. Über das Verhalten des Hausschweines unter besonderer Berücksichtigung des Fortpflanzungsverhaltens, Inaugural-Dissertation, Freie Universität Berlin, Berlin.

Grunau, R.V.E., Johnston, C.C., Craig, K.D., 1990. Neonatal facial and cry responses to invasive and non-invasive procedures. Pain 42, 295-305.

Kennedy, J.S., 1992. The New Anthropomorphism. Cambridge Univ. Press, Cambridge, UK.

Lay, D.C. Jr., Friend, T.H., Bowers, C.L., Grissom, K.K., Jenkins, O.C., 1992a. A comparative physiological and behavioral study of freeze and hot-iron branding using dairy cows. J. Anim. Sci. 70, 1121-1125.

Lay, D.C. Jr., Friend, T.H., Grissom, K.K., Bowers, C.L., Mal, M.E., 1992b. Effects of freeze or hot-iron branding of Angus calves on some physiological and behavioral indicators of stress. Appl. Anim. Behav. Sci. 33, 137-147.

Lineberry, C.G., 1981. Laboratory animals in pain research. In: Gay, W.I. (Ed.), Methods in Animal Experimentation, Vol. VI. Academic Press, New York, pp. 237-311.

Mellor, D.J., 1991. Effects of castration on behaviour and plasma cortisol concentrations in young lambs, kids and calves. Res. Vet. Sci. 51, 149-154.

Morton, D.B., Griffiths, P.H.M., 1985. Guidelines on the recognition of pain, distress and discomfort in experimental animals and an hypothesis for assessment. Vet. Rec. 116, 431-436.

Noonan, G.J., Rand, J.S., Priest, J., Blackshaw, J.K., 1994. Behavioural observations of piglets undergoing tail docking, teeth clipping and ear notching. Appl. Anim. Behav. Sci. 39, 203-213. 
Noonan, G.J., Rand, J.S., Blackshaw, J.K., Priest, J., 1996. Behavioural observations of puppies undergoing tail docking. Appl. Anim. Behav. Sci. 49, 335-342.

Porter, F.L., Miller, R.H., Marshall, R.E., 1986. Neonatal pain cries: effect of circumcision on acoustic features and perceived urgency. Child. Dev. 57, 790-802.

Porter, F.L., Porges, S.W., Marshall, R.E., 1988. Newborn pain cries and vagal tone: parallel changes in response to circumcision. Child. Dev. 59, 495-505.

Redondo, T., Castro, F., 1992. Signalling of nutritional need by magpie nestlings. Ethology 92, 193-204.

Stafleu, F.R., Rivas, E., Rivas, T., Vorstenbosch, J., Heeger, F.R., Beynen, A.C., 1992. The use of analogous reasoning for assessing discomfort in laboratory animals. Anim. Welfare 1, 77-84.

Weary, D.M., Fraser, D., 1995. Calling by domestic piglets: reliable signals of need? Anim. Behav. 50, 1046-1055.

Weary, D.M., Lawson, G., Thompson, B.K., 1996. Sows show stronger responses to isolation calls of piglets associated with greater levels of piglet need. Anim. Behav. 52, 1247-1253.

Wemelsfelder, F., van Putten, G., 1985. Behaviour as a Possible Indicator for Pain in Piglets. Instituut voor Veeteeltkundig Onderzoek 'Schoonoord', Report B-260, Zeist, The Netherlands.

White, R.G., DeShazer, J.A., Tressler, C.J., Borcher, G.M., Davey, S., Waninge, A., Parkhurst, A.M., Milanuk, M.J., Clemens, E.T., 1995. Vocalization and physiological response of pigs during castration with or without a local anaesthetic. J. Anim. Sci. 73, 381-386. 